\title{
Aqueous Ammonia Soaking of Wheat Straw at ambient temperature for Enhancing the Methane Yield: Process Optimization by Response Surface Methodology
}

\author{
Lymperatou, Anna; Gavala, Hariklia N.; Skiadas, loannis V.
}

Published in:

Waste and Biomass Valorization

Link to article, DOI:

$10.1007 / \mathrm{s} 12649-019-00806-7$

Publication date:

2020

Document Version

Peer reviewed version

Link back to DTU Orbit

Citation (APA):

Lymperatou, A., Gavala, H. N., \& Skiadas, I. V. (2020). Aqueous Ammonia Soaking of Wheat Straw at ambient temperature for Enhancing the Methane Yield: Process Optimization by Response Surface Methodology. Waste and Biomass Valorization, 11, 4821-4835. https://doi.org/10.1007/s12649-019-00806-7

\section{General rights}

Copyright and moral rights for the publications made accessible in the public portal are retained by the authors and/or other copyright owners and it is a condition of accessing publications that users recognise and abide by the legal requirements associated with these rights.

- Users may download and print one copy of any publication from the public portal for the purpose of private study or research.

- You may not further distribute the material or use it for any profit-making activity or commercial gain

- You may freely distribute the URL identifying the publication in the public portal 


\title{
“Aqueous Ammonia Soaking of Wheat Straw at ambient temperature for Enhancing the Methane Yield: Process Optimization by Response Surface Methodology”
}

\author{
Anna Lymperatou, Hariklia N. Gavala, Ioannis V. Skiadas* \\ Department of Chemical and Biochemical Engineering, Technical University of Denmark \\ Søltofts Plads, Building 229, Kongens Lyngby 2800, Denmark \\ *ivsk@kt.dtu.dk, ioannis_sk@yahoo.co.uk
}

\begin{abstract}
Aqueous Ammonia Soaking (AAS) at ambient temperature was applied to wheat straw under different conditions in order to maximize the $\mathrm{CH}_{4}$ yield through mesophilic anaerobic digestion. The effects of the $\mathrm{NH}_{3}$ concentration, duration of AAS and solid-to-liquid ratio were studied on the resulting $\mathrm{CH}_{4}$ yield and the solubilization degree of the pretreated wheat straw. A strong interaction among the $\mathrm{NH}_{3}$ concentration and the duration of AAS was observed. The optimal conditions found were $18 \% \mathrm{w} / \mathrm{w} \mathrm{NH}_{3}, 7$ days of duration and $50 \mathrm{~g}$ straw/ $\mathrm{L}$ reagent, leading to a $43 \%$ increase of the $\mathrm{CH}_{4}$ yield in 17 days of digestion. Compositional analysis of the optimally-treated wheat straw revealed that a significant solubilization of hemicellulose took place during AAS together with a moderate lignin removal (9\%).
\end{abstract}

Keywords: wheat straw, pretreatment, anaerobic digestion, optimization, aqueous ammonia soaking, methane 


\section{Graphical Abstract}

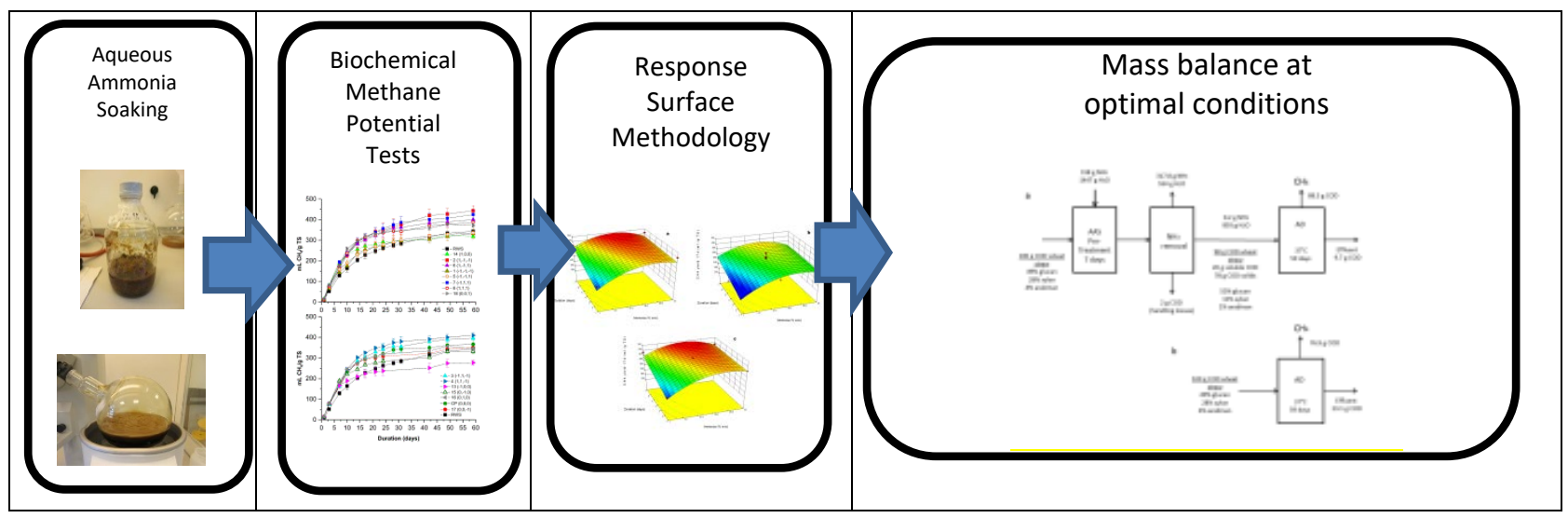




\section{Statement of novelty}

In this study, the response surface methodology was followed for optimizing the aqueous ammonia soaking pretreatment of wheat straw at ambient temperature in order to maximize the methane yield. The optimal conditions of the pretreatment found to lead to the highest methane yield, showed that a significant enhancement of the methane yield can be achieved without heat application, while the compositional analysis of the pretreated biomass confirmed the importance of digesting both the solid and liquid fraction. Overall, the empirical models constructed were able to predict the methane yield and the solubilization of wheat straw as a function of the pretreatment duration, solid to liquid ratio and ammonia concentration and provide valuable tools for assessing different process configurations.

\section{Introduction}

A greener energy production system is forthcoming, as numerous countries worldwide have set goals for achieving a shift from fossil fuels to renewable energy sources in the near future. Specifically in the EU, there is a target of achieving a 20\% share of the energy consumption to originate from renewable resources until 2020 [1]. Bioenergy is expected to cover $60 \%$ of the total renewable energy production until then [2]. In this line, agricultural residues such as straw constitute an important source for energy production, due to their high availability. Among other applications, straw has been traditionally used in animal breeding as feed and as bedding material, as well as incorporated to the soil for reducing erosion risk and improving soil fertility [3]. Taking into account the amount of residues used for sustainable agricultural practices, in addition to competitive uses of these residues, Scarlat et al. [3] have calculated the average annual energy potential of crop residues in Europe to reach 1537 PJ. In Europe the most abundant agricultural straw originates from wheat crop, which is also the second most abundant worldwide [4]. The conversion of wheat straw into energy is possible through various processes, such as combustion, gasification, fermentation to produce ethanol and anaerobic digestion (AD) for biogas production [5]. 
Among the renewable energy products, biogas is expected to contribute with a $12 \%$ share of the European bioenergy platform of 2020 [2]. Wheat straw has been identified as a suitable co-substrate to other organic residues that are usually sent to $\mathrm{AD}$ plants e.g. livestock manure [6-9], as it can improve the $\mathrm{C} / \mathrm{N}$ ratio, boost the biogas production and increase the dry matter loading of liquid waste streams. An additional advantage of using wheat straw as a substrate for $\mathrm{AD}$ is that the carbon remaining in the digestate can be returned to the soil, reducing this way direct competition with the practice of incorporating straw to the soil. The digestion of wheat straw for biogas production has been studied in the past under both mesophilic and thermophilic conditions and with various sources of inoculum [10-13]. Nevertheless, the conversion to biogas is limited due to the rigid lignocellulosic structure of wheat straw that restricts access to microbial enzymes impeding thus hydrolysis, the first step of AD. This fact leads to the necessity of applying a pretreatment in order to increase the digestibility of wheat straw. During the last years, numerous pretreatment strategies have been proposed for improving the bioconversion of lignocellulosic biomasses. These include physical, chemical, biological or combinatorial methods. Several reviews have been published presenting the different approaches and their specific characteristics [14-16]. While some pretreatment methods have proven to be very efficient on improving the bioconversion of biomasses, the increased cost of their implementation due to high energy input or due to the consumption of chemicals often restricts their potential application at industrial scale.

Aqueous ammonia soaking (AAS) is identified as a pretreatment with a great potential to be applied on lignocellulosic biomasses for improving their conversion to biofuels. Ammonia is known to cause delignification or swelling of lignocellulose, rendering this way the biomass more easily convertible to the desired products. However, the main advantage of AAS is the possibility of recovering and reusing ammonia, avoiding thus the addition of chemicals for $\mathrm{pH}$ correction of the pretreated biomass [17]. As a result, the cost of chemicals of the pretreatment is reduced. Extensive work has been carried out lately on AAS of different lignocellulosic biomasses for improving ethanol [18] and biogas production [11, 20-28]. Particularly in the case of wheat straw, ammonia pretreatments for improving the production of biogas have been tested in the past $[11,24,26]$. Nevertheless, in 
these studies the ammonia pretreatment was performed under relatively high temperatures. AAS at ambient temperature can present certain advantages over other configurations of ammonia treatment. Usually temperature less than $80^{\circ} \mathrm{C}$ is considered not to involve extra energy input, as the waste heat from the gas engines can be used [26]. However, in a chemical pretreatment where $\mathrm{NH}_{3}$ is expected to be recovered, the waste heat could be more efficiently used when applied to the end of the pretreatment for facilitating the $\mathrm{NH}_{3}$ recovery process. Moreover, when thermal alkaline pretreatments are applied on lignocellulosic biomasses, there is an increased risk of formation of inhibitory by-products [15]. Although $\mathrm{AD}$ might be less sensitive to these inhibitors than fermentation, an estimation of such effect was not possible in previous studies since the pretreated straw was washed and only the solid fraction was digested [26]. This approach can also lead to a reduced methane yield due to the organic fraction that is solubilized and thus removed during washing. Overall, the expected low energy consumption (given ambient temperature and pressure is applied), in combination with the possibility of recovering ammonia, makes AAS a good candidate for application to wheat straw, minimizing the cost of implementation at a large scale. Previous experiments of AAS at ambient temperature (where both liquid and solid fractions were used for digestion) have shown that the methane yield of the pretreated biomass was significantly higher than the untreated biomass [22]. However, the pretreatment was tested only under one set of conditions and a further investigation of the effects of the AAS parameters could give an insight on the different possible configurations of the pretreatment.

In this study, the influence of the AAS parameters on the resulting short term and ultimate methane yield of pretreated wheat straw was investigated. The effect of AAS on the solubilization and the hydrolysis rate of wheat straw were also evaluated. Response Surface Methodology (RSM) was applied in order to produce empirical models for predicting the methane yield and the degree of solubilization of the treated straw as functions of the AAS parameters. Finally, the optimal pretreatment conditions at ambient temperature leading to the highest conversion of wheat straw to methane were determined. 


\section{Materials and Methods}

\subsection{Substrate and Inoculum}

The wheat straw used for the experiments was harvested from Sjæland region in Denmark and was stored in big bales in a dry and dark room. Prior to use, it was milled to $6 \mathrm{~mm}$ by a cutting mill (Retsch SM 2000, Germany). The total solids (TS) content of the wheat straw were $93.75 \pm 0.22 \%$ of wet mass and the Volatile Solids (VS) $89.21 \pm 0.55 \%$ of wet mass (corresponding to $95.16 \%$ TS). The total Chemical Oxygen Demand (COD) of the wheat straw was $1.25 \pm 0.14 \mathrm{~g} \mathrm{O}_{2} / \mathrm{g}$ VS. By assuming $350 \mathrm{~mL} \mathrm{CH}_{4} / \mathrm{g} \mathrm{COD}$ (at STP conditions, $0^{\circ} \mathrm{C}, 1 \mathrm{~atm}$ ), the theoretical $\mathrm{CH}_{4}$ yield was calculated to be $436 \mathrm{~mL} / \mathrm{g}$ VS (at STP conditions) and $468 \mathrm{~mL} / \mathrm{g}$ VS at $20^{\circ} \mathrm{C}$. The inoculum used for the Biochemical Methane Potential (BMP) tests originated from a centralized full-scale biogas plant digesting livestock manure and organic waste under mesophilic conditions (Hashøj Biogas, Denmark). The inoculum was incubated at $37^{\circ} \mathrm{C}$ for 10 days prior to use for reducing the residual biogas production. The main characteristics of the inoculum were 2.77\% TS, 1.49\% VS, $2.86 \mathrm{~g} \mathrm{NH}_{4}{ }^{+}-\mathrm{N} / \mathrm{L}, 8.04 \mathrm{~g}$ soluble COD/L, and pH 8.0.

\subsection{AAS pretreatment}

The different pretreatment batches of wheat straw took place in $2 \mathrm{~L}$ screw-capped laboratory bottles. The solution of aqueous ammonia (reagent) was added and the bottles were sealed for avoiding losses of ammonia reagent. The mixture was left intact (no mixing) until the end of the pretreatment. At the end of the pretreatment duration, the ammonia was removed by vacuum evaporation (Buchi Rotavapor, Switzerland) at 130 mbar while the temperature of the water bath was progressively increased up to $80^{\circ} \mathrm{C}$. Prior to the evaporation step, an equal volume of tap water was added to the mixture for facilitating the handling of the biomass and the vacuum evaporation of $\mathrm{NH}_{3}$. Preliminary experiments indicated that there was no effect of the evaporation process itself on the $\mathrm{CH}_{4}$ yield [28]. The final concentration of $\mathrm{NH}_{4}{ }^{+}-\mathrm{N}$ in all batches after evaporation was less than $0.8 \mathrm{~g} / \mathrm{L}$ securing thus that no inhibitory effect would occur during the subsequent AD step. 


\subsection{BMP tests}

The BMP tests were set with $1.0 \mathrm{~g}$ TS of wheat straw and $40 \mathrm{~mL}$ of inoculum in $320 \mathrm{~mL}$ infusion bottles. Due to difficulties on representative sampling of the pretreated straw, the pretreated biomass was separated to a solid and a liquid fraction. For this, the pretreated mixture was passed through $1 \mathrm{~mm}$ sieve placed on top of a $2 \mathrm{~L}$ beaker. When no more liquid was dripping from the sieve to the beaker, the solids were transferred to a pre-weighed box with a lid and the liquid was transferred volumetrically to a $1 \mathrm{~L}$ blue-cap bottle. Subsequently, the respective amount of the solid and liquid fraction was added to the BMP bottle based on the mass/volume $(\mathrm{m} / \mathrm{v})$ ratio of the initial pretreated batch. The BMP tests were set up in two blocks. In each block of experiments, two additional BMP tests were set up, one with inoculum and raw wheat straw (RWS), used as control, and one only with inoculum used as blank. All BMP tests were set at triplicates. The bottles were flushed with a mixture of $80 \%$ $\mathrm{N}_{2} / 20 \% \mathrm{CO}_{2}$, sealed with rubber stoppers, secured with aluminum crimps and placed in an incubator at $37^{\circ} \mathrm{C}$. The $\mathrm{CH}_{4}$ production was monitored periodically until the end of the experiments. Gas samples of $200 \mu \mathrm{L}$ volume were collected from the headspace of the vials by means of a gas-tight syringe and injected to a gas chromatograph (see section 2.6). The $\mathrm{CH}_{4}$ production of the BMP tests of both pretreated and RWS was corrected for the residual production of the inoculum by subtracting the $\mathrm{CH}_{4}$ production of the blank tests. Values of $\mathrm{CH}_{4}$ yield reported are given at $20^{\circ} \mathrm{C}$, unless otherwise mentioned and correspond to average yields of triplicates along with the standard deviation. The hydrolysis rate is considered to be the limiting step in AD of lignocellulosic substrates and first order kinetics can thus be used for describing the hydrolysis process [29]. The hydrolysis rates $k$ of the BMP tests were calculated as described in [29] by applying equation 1 to each BMP test.

$$
B=B_{0}\left(1-e^{-k t}\right),(\text { eq.1) }
$$

where $B$ and $B_{0}$ correspond to the $\mathrm{CH}_{4}$ yield after $t$ days of digestion and the ultimate $\mathrm{CH}_{4}$ yield of the sample added, respectively. The criterion for choosing the duration $t$ for each BMP was that the $\mathrm{CH}_{4}$ production had reached the $65 \%$ of the ultimate value, $B=0.65 B_{0}$. 


\subsection{Experimental Design and data analysis}

In order to study the effects of the AAS parameters on the $\mathrm{CH}_{4}$ yield of pretreated wheat straw, a faced Central Composite Design (CCD) was followed and the results were analyzed by RSM. The software used for the analysis was Design Expert 9.0.6.2 (Stat-Ease, USA). Three parameters of AAS were chosen as independent variables, namely the $\mathrm{NH}_{3}$ concentration of the reagent, the duration of AAS and the solid-to-liquid (S:L) ratio. This approach permitted following a structured experimental design where the 3 parameters were set at 3 different levels (Table 1) and the main and quadratic effects of each parameter as well as any interaction effects among the latter could be estimated with a relatively small number of experiments, by taking advantage of the geometry of the experimental region. Additionally, one set of conditions (center point) was repeated 6 times in order to estimate the variation of the response including all experimental errors, and this has been taken into account by the software for the construction of the model. Finally, an empirical equation was constructed, where the response was expressed as a function of the significant effects as detected from the statistical analysis. This equation has the following general form:

$$
Y=b_{0}+b_{1} x_{1}+b_{2} x_{2}+b_{3} x_{3}+b_{12} x_{1} x_{2}+b_{13} x_{1} x_{3}+b_{23} x_{2} x_{3}+b_{11} x_{1}^{2}+b_{22} x_{2}^{2}+b_{33} x_{3}^{2} \text { (eq.2) }
$$

Where

$Y$, is the dependent parameter (response);

$x_{i}, \mathrm{i}=1,2,3$ are the independent parameters;

$b_{0}$ is the intercept coefficient;

$b_{i}, \mathrm{i}=1,2,3$ are the regression coefficients expressing the main effect of each parameter on the response;

$b i j, \mathrm{i}, \mathrm{j}=1,2,3, \mathrm{j} \neq \mathrm{i}$, are the regression coefficients for the interaction effect of 2 independent parameters on the response; 
$b_{i i}, \mathrm{i}=1,2,3$, are the regression coefficients for the quadratic effect of each independent parameter on the response.

The regression coefficients were calculated by regression analysis of the experimental data. The model obtained was assessed by ANOVA and statistical significance was tested by Fisher's F-test. All terms expressing main effects were included in the final models, while only interaction and quadratic effects found statistically significant ( $p$ value $<0.05$ ) were included. Based on the empirical model obtained, a response surface graph was constructed where the predicted response was plotted as a function of two independent parameters in a three-dimension graph.

Table 1 Levels of parameters based on the CCD followed for the optimization of AAS of wheat straw

\begin{tabular}{lccc} 
AAS Parameter & Low & Center & High \\
& level & level & level \\
\hline & $\mathbf{- 1}$ & $\mathbf{0}$ & $\mathbf{1}$ \\
$\mathbf{A}-\mathrm{NH}_{3}$ concentration* (\% w/w) & 1 & 16.5 & 32 \\
$\boldsymbol{D}$ - Duration of AAS (days) & 1 & 4 & 7 \\
$\mathbf{S L}$ - Solid-to-liquid ratio (g straw/L reagent) & 50 & 75 & 100 \\
\hline & & &
\end{tabular}

\subsection{Compositional analysis}

Compositional analysis was performed on both RWS and optimally AAS-treated wheat straw. All analyses were performed at least in duplicates and the average values are reported accompanied with the standard deviation. The pretreated wheat straw was dried at $45^{\circ} \mathrm{C}$ and both raw and dried pretreated biomasses were ground to $1 \mathrm{~mm}$ by a laboratory grinder (IKA, MF 10.1, IKA®-Werke GmbH). The biomasses were subjected to a two-step extraction process, first with Millipore-grade water for 6 hours and subsequently with 96\% v/v ethanol for 24 hours, according to Sluiter et al. [30]. The extracted biomasses were used for determination of structural carbohydrates 
and lignin (acid-insoluble and acid-soluble) following the two step acid hydrolysis procedure according to Sluiter et al. [31]. Acid-soluble lignin was measured at $205 \mathrm{~nm}$ and the absorptivity $\varepsilon(35.94 \mathrm{~L} / \mathrm{g} \cdot \mathrm{cm})$ was determined following NREL's protocol [32].

Determination of soluble components of RWS was carried out by soaking the straw in water for 24 hours while for the pretreated straw, the liquid fraction after the $\mathrm{NH}_{3}$ removal step was used. Both mixtures (water-straw and pretreated straw) were centrifuged at 10,000 rpm for $10 \mathrm{~min}$ and subsequently filtered to pass through a $0.45 \mu \mathrm{m}$ membrane filter. Free sugars were determined in the liquid samples and oligosaccharides were determined after a dilute-acid hydrolysis step as described in Bjerre et al. [33]. Free sugars were determined after acidifying liquid samples with $0.1 \mathrm{M} \mathrm{H}_{2} \mathrm{SO}_{4}$ and filtering through $0.22 \mu \mathrm{m}$ membrane filters. Both raw and pretreated biomasses were analyzed for their composition in C, H, N, O, by an Elemental analyzer (EuroVector, Model EA 3000). Acetanilide was used as a standard.

\subsection{Analytical Methods}

TS, VS and ash determination was carried out according to APHA [34]. $\mathrm{NH}_{4}{ }^{+}-\mathrm{N}$ and soluble COD determination was performed after the $\mathrm{NH}_{3}$ evaporation step by Hach Lange kit LCK 305 and LCK 514 respectively; samples of the pretreated straw were centrifuged at $10,000 \mathrm{rpm}$ for $10 \mathrm{~min}$ and filtered through $0.45 \mu \mathrm{m}$. For the total COD determination, the wheat straw was milled to powder with a commercial coffee grinder and diluted with Milliporegrade water. All determinations were based on triplicates. Measurement was done by Hach Lange kit LCK 514. Carbohydrate and acetic acid quantification was performed by High Performance Liquid Chromatography (HPLC) with a refractive index and an Aminex HPX-87H column (BioRad) at $63^{\circ} \mathrm{C}$. A solution of $12 \mathrm{mM} \mathrm{H}_{2} \mathrm{SO}_{4}$ was used as eluent at a flow rate of $0.6 \mathrm{~mL} / \mathrm{min}$. The detection and quantification of $\mathrm{CH}_{4}$ was performed by Gas Chromatography (GC) with a Porapak Q packed column (6 ft. and I.D. 3 mm) and a Thermal Conductivity Detector (TCD) and $\mathrm{N}_{2}$ was used as carrier gas. The temperature of the injector, the oven and the detector were all set at 70 ${ }^{\circ} \mathrm{C}$. 


\section{Results and Discussion}

\subsection{COD solubilization of AAS-treated wheat straw}

The effect of AAS on wheat straw at ambient temperature was evaluated by pretreating twenty different batches under varying $\mathrm{NH}_{3}$ concentration, duration of AAS and S:L ratio. The pretreatment produced significant solubilization of the solid matrix, ranging from 7.27 to $23.60 \%$ of total COD (Table 2). As anticipated, the extent of solubilization was dependent on the conditions in a way that harsher conditions, such as high $\mathrm{NH}_{3}$ concentration or high duration of AAS, produced higher soluble CODs. For instance, the COD solubilized after the experiments performed at $1 \% \mathrm{w} / \mathrm{w} \mathrm{NH}_{3}$ did not exceed the $12 \%$ of the total COD (Table 2). From previous studies on lignocellulosic biomasses, it is known that AAS often results in solubilization of lignin and hemicellulose [18]. This effect is expected to improve the access of enzymes to polysaccharides (cellulose and hemicellulose), while the solubilized fraction may comprise of valuable organic matter (e.g. oligosaccharides) that can easily be converted to $\mathrm{CH}_{4}$ or inhibitory degradation products. Severe inhibition though is not that likely in AD as the usual degradation products of pretreated lignocellulosic biomasses such as HMF, furfurals, lignin polymers and derivatives have shown not to cause complete inhibition [35]. Consequently, if only the solid fraction is used for digestion, a significant loss of biogas or $\mathrm{CH}_{4}$ could occur. In this sense, depending on the desired configuration of the pretreatment, low severity pretreatment could be more favorable for improving the $\mathrm{CH}_{4}$ yield of wheat straw, while harsher conditions of AAS could improve the initial rate of $\mathrm{CH}_{4}$ production from the entire biomass (liquid and solid fractions of wheat straw).

\subsection{BMP tests}

The BMP experiments of the AAS-treated wheat straw lasted 59 days, after which no significant $\mathrm{CH}_{4}$ production was observed. As shown in Fig.1, AAS resulted in an improved production rate within the first 7 days in all batches of pretreated wheat straw. The BMP tests of the RWS reached $65 \%$ of their ultimate $\mathrm{CH}_{4}$ yield within $17-21$ days 
of digestion and the pretreated wheat straw within 10-14 days of digestion, reducing thus significantly the duration of $\mathrm{AD}$. The high $\mathrm{R}^{2}$ of the fit of the experimental data confirms that assuming $1^{\text {st }}$ order kinetics is justified (Table 2). Hence, assuming that the hydrolysis of the biomass is the rate-limiting step in the $\mathrm{AD}$ of wheat straw, the pretreatment not only solubilized the solid matrix, but also improved the hydrolysis of lignocellulose during AD. The RWS averaged a hydrolysis rate of $0.0655 \mathrm{~d}^{-1}$, while the rate of the pretreated straw ranged from $0.0802 \mathrm{~d}^{-1}$ to $0.1346 \mathrm{~d}^{-1}$, resulting thus in an more than 2-fold increase. The highest increase of hydrolysis rate corresponded to experiment 14, where AAS was applied at $32 \% \mathrm{w} / \mathrm{w}$ of $\mathrm{NH}_{3}$ concentration and at the center levels of duration and S:L ratio. Nevertheless, different biodegradability degrees have been obtained among batches, resulting to different ultimate $\mathrm{CH}_{4}$ yields (Table 2). Consequently, the highest hydrolysis rate does not correspond necessarily to the experiment with the highest short term $\mathrm{CH}_{4}$ yield.

The RWS used in this study produced totally an average of $343.44 \mathrm{~mL} / \mathrm{g}$ TS (Table 2). As indicated by the difference in the ultimate $\mathrm{CH}_{4}$ yields (after 59 days of AD) among pretreated batches (Table 2), the AAS pretreatment affected the biodegradability of wheat straw in different ways when applied under different conditions. The range of cumulative $\mathrm{CH}_{4}$ yield of the AAS-pretreated wheat straw varied from $277 \mathrm{~mL} / \mathrm{g}$ TS to $443 \mathrm{~mL} / \mathrm{g}$ TS, producing thus negative and positive effects on the digestibility of the biomass depending on the conditions. Generally, the higher increases of the ultimate $\mathrm{CH}_{4}$ yield were observed from the batches that were treated with high $\mathrm{NH}_{3}$ concentrations or for high AAS durations (e.g. experiments 2, 3, 4, 6 and 7). This is a result of the reaction between the $\mathrm{NH}_{3}$ and the biomass, improving thus the availability of lignocellulosic parts that would otherwise be unavailable for conversion.

The effect of the pretreatment on the ultimate $\mathrm{CH}_{4}$ yields mainly shows how the final digestibility of the biomass is affected, and indicates the potential production from the biomass. Although an increase of the total digestibility of a biomass is desirable, it can be a poor indicator for the increase of the $\mathrm{CH}_{4}$ yield on an $\mathrm{AD}$ process where the Hydraulic Retention Time (HRT) would be desirable to be reduced to 15-20 days [36]. Hence, the effect of the AAS parameters on the short term $\mathrm{CH}_{4}$ yield is of interest from an application point of view. Therefore taking into 
account that the hydrolysis of the biomass will be more efficient after the pretreatment and in order to secure methanogens growth in a CSTR-type digester, the $\mathrm{CH} 4$ yield at 17 days of digestion was chosen for modeling

The short term $\mathrm{CH}_{4}$ yield of the BMP experiments of AAS-treated wheat straw varied from $223 \mathrm{~mL} / \mathrm{g}$ TS to 325 $\mathrm{mL} / \mathrm{g}$ TS, and the RWS resulted in an average $\mathrm{CH}_{4}$ yield of $228 \mathrm{~mL} / \mathrm{g}$ TS (Table 2). In all cases except experiment 13, the pretreatment resulted in an increase of the short term $\mathrm{CH}_{4}$ yield, reaching a maximum of $51 \%$ (experiment 4). Experiment 13 resulted in less short term $\mathrm{CH}_{4}$ yield than the raw biomass (-7\%) as well as in a lower ultimate $\mathrm{CH}_{4}$ yield. In previous studies, negative effects on the biogas yield have been reported [26]; however this was a result of digesting only the solid fraction after the pretreatment. When harsh conditions are applied, a higher COD content would be solubilized, thus a negative yield would be obtained as commented also in section 3.1. This cannot be the case in this study though, as AAS at experiment 13 was applied at mild conditions (1\% w/w $\mathrm{NH}_{3}, 4$ days). The main reason for this observation might be that practically AAS resulted in no net improvement of digestibility as the $\mathrm{NH}_{3}$ concentration was very low and not compensated by the highest duration.

As commented in section 1, AAS has been applied to numerous biomasses for improving their AD, and it has been proved that the type of biomass affects the efficiency of AAS. For instance, biomasses like swine manure fibers [21], digested manure fibers [23], miscanthus, wheat straw, willow [22], grass, poplar and sunflower straw [27] have resulted in an increase of $\mathrm{CH}_{4}$ yield varying from $25 \%$ to $265 \%$ when pretreated by the same AAS procedure. However, as seen in this study and also elsewhere [26, 37], the efficiency of the pretreatment depends largely on the conditions applied. In this sense, RSM is a powerful tool for obtaining information on how different parameters affect a desired response, i.e. how the AAS parameters $\left(\mathrm{NH}_{3}\right.$ concentration, duration of AAS and S:L ratio) affect the $\mathrm{CH}_{4}$ yield of the pretreated wheat straw, and what is the maximum increase that can be obtained within the desired limits of each parameter. 


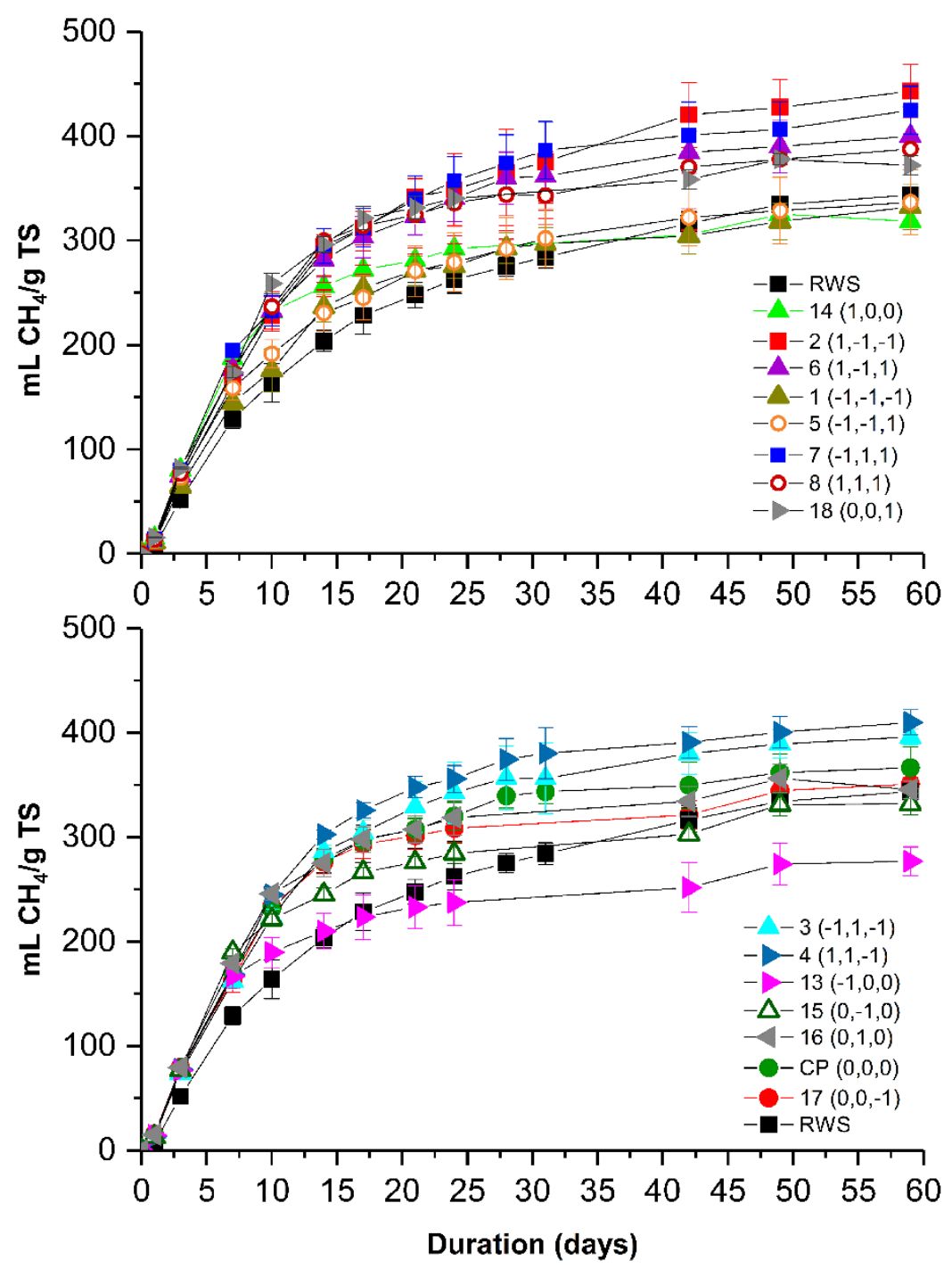

Fig. 1 Graph of cumulative methane yields of BMP tests of AAS-treated wheat straw under different pretreatment conditions during digestion experiments. Numbers of experiments correspond to different AAS conditions explained in Table 2 and numbers in parentheses correspond to the coded values of the design as shown in Table 1. Points correspond to average values from triplicates and vertical bars to standard deviation. 
Table 2 Experimental conditions and results of wheat straw pretreated with AAS under different conditions following the CCD. RWS stands for raw wheat straw. Experiments from 1 to 12 and RWS 1 correspond to the $1^{\text {st }}$ block of BMPs, and experiments from 13 to 20 and RWS 2 correspond to the $2^{\text {nd }}$ block. Values for $\mathrm{CH}_{4}$ yields reported correspond to average yields with the standard deviation of triplicates. Numbers in parentheses next to hydrolysis rates correspond to the $\mathrm{R}^{2}$ of the fit of experimental data to the $1^{\text {st }}$ order equation.

\begin{tabular}{|c|c|c|c|c|c|c|c|c|c|c|}
\hline $\begin{array}{c}\text { No. of } \\
\text { experiment }\end{array}$ & $\begin{array}{c}\mathrm{NH}_{3} \\
\text { concentration } \\
(\% \mathrm{w} / \mathrm{w})\end{array}$ & $\begin{array}{l}\text { Duration } \\
\text { of AAS } \\
\text { (days) }\end{array}$ & $\begin{array}{c}\text { Solid-to } \\
\text { Liquid } \\
\text { ratio } \\
(\mathrm{g} / \mathrm{L})\end{array}$ & $\begin{array}{c}\text { COD } \\
\text { solubilized } \\
\text { (\% total } \\
\text { COD) }\end{array}$ & $\begin{array}{c}\mathrm{CH}_{4} \text { yield } \\
\text { 17d (mL } \\
\left.\mathrm{CH}_{4} / \mathrm{g} \mathrm{TS}\right)\end{array}$ & $\begin{array}{c}\mathrm{CH}_{4} \text { yield } \\
\text { 17d (mL } \\
\left.\mathrm{CH}_{4} / \mathrm{g} \mathrm{VS}\right)\end{array}$ & $\begin{array}{c}\% \\
\text { increase } \\
\mathrm{CH}_{4} \\
\text { yield } 17 \mathrm{~d}\end{array}$ & $\begin{array}{c}\text { Ultimate } \mathrm{CH}_{4} \\
\text { yield (mL } \\
\mathrm{CH}_{4} / \mathrm{g} \mathrm{TS} \text { ) }\end{array}$ & $\begin{array}{c}\text { Ultimate } \mathrm{CH}_{4} \\
\text { yield (mL } \\
\left.\mathrm{CH}_{4} / \mathrm{g} \mathrm{VS}\right)\end{array}$ & $\begin{array}{c}\text { Hydrolysis rate } \\
\qquad\left(d^{-1}\right)\left(R^{2}\right)\end{array}$ \\
\hline 1 & 1 & 1 & 50 & 7.18 & $254.67 \pm 10.95$ & $265.75 \pm 11.43$ & 18.1 & $332.06 \pm 21.36$ & $346.50 \pm 22.29$ & $0.0802(0.992)$ \\
\hline 2 & 32 & 1 & 50 & 18.27 & $320.60 \pm 15.99$ & $341.08 \pm 17.01$ & 44.6 & $443.01 \pm 25.42$ & $490.23 \pm 27.04$ & $0.0814(0.995)$ \\
\hline 3 & 1 & 7 & 50 & 11.75 & $304.45 \pm 12.51$ & $337.56 \pm 13.87$ & 41.2 & $395.78 \pm 7.62$ & $438.82 \pm 8.45$ & $0.0915(0.992)$ \\
\hline 4 & 32 & 7 & 50 & 21.70 & $325.59 \pm 6.96$ & $345.27 \pm 7.39$ & 51.0 & $409.93 \pm 12.08$ & $434.70 \pm 12.81$ & $0.0967(0.990)$ \\
\hline 5 & 1 & 1 & 100 & 7.27 & $245.30 \pm 21.02$ & $258.81 \pm 22.18$ & 13.8 & $336.55 \pm 31.24$ & $355.10 \pm 32.97$ & $0.0849(0.996)$ \\
\hline 6 & 32 & 1 & 100 & 12.49 & $303.18 \pm 19.85$ & $320.58 \pm 20.99$ & 40.6 & $400.02 \pm 27.62$ & $422.97 \pm 29.21$ & $0.0896(0.998)$ \\
\hline 7 & 1 & 7 & 100 & 9.34 & $312.26 \pm 18.28$ & $331.70 \pm 19.42$ & 44.8 & $424.74 \pm 22.84$ & $451.18 \pm 24.26$ & $0.0858(0.996)$ \\
\hline 8 & 32 & 7 & 100 & 22.50 & $313.92 \pm 13.53$ & $331.39 \pm 14.28$ & 45.6 & $387.53 \pm 14.59$ & $409.10 \pm 15.40$ & 0.1057 (0.989) \\
\hline 9 & 16.5 & 4 & 75 & 23.60 & $291.00 \pm 20.32$ & $327.01 \pm 22.83$ & 35.0 & $364.52 \pm 15.00$ & $409.62 \pm 16.86$ & 0.0879 (0.992) \\
\hline 10 & 16.5 & 4 & 75 & 17.04 & $296,56 \pm 28.10$ & $317.22 \pm 30.10$ & 37.6 & $372.19 \pm 33.88$ & $398.12 \pm 36.24$ & $0.0972(0.998)$ \\
\hline 11 & 16.5 & 4 & 75 & 15.80 & $295.14 \pm 8.57$ & $309.58 \pm 8.98$ & 36.9 & $375.04 \pm 3.96$ & $393.39 \pm 4.15$ & $0.0975(0.996)$ \\
\hline 12 & 16.5 & 4 & 75 & 17.84 & $315.29 \pm 12.29$ & $333.79 \pm 13.01$ & 46.2 & $395.81 \pm 11.93$ & $419.04 \pm 12.63$ & $0.0986(0.987)$ \\
\hline 13 & 1 & 4 & 75 & 9.04 & $223.40 \pm 21.53$ & $238.08 \pm 22.95$ & -7.3 & $276.96 \pm 18.90$ & $295.16 \pm 14.58$ & $0.1231(0.988)$ \\
\hline 14 & 32 & 4 & 75 & 19.87 & $271.96 \pm 4.46$ & $287.72 \pm 4.72$ & 12.9 & $318.49 \pm 13.68$ & $336.94 \pm 8.54$ & $0.1346(0.994)$ \\
\hline 15 & 16.5 & 1 & 75 & 11.54 & $266.42 \pm 4.71$ & $282.21 \pm 4.99$ & 10.6 & $331.75 \pm 10.30$ & $351.43 \pm 10.91$ & 0.1175 (0.989) \\
\hline 16 & 16.5 & 7 & 75 & 19.69 & $297.71 \pm 12.34$ & $315.75 \pm 13.09$ & 23.6 & $345.52 \pm 8.38$ & $366.46 \pm 8.89$ & $0.1241(0.986)$ \\
\hline 17 & 16.5 & 4 & 50 & 19.90 & $293.42 \pm 13.75$ & $313.88 \pm 14.71$ & 21.8 & $355.25 \pm 6.00$ & $375.23 \pm 6.41$ & $0.1060(0.985)$ \\
\hline 18 & 16.5 & 4 & 100 & 17.15 & $321.29 \pm 11.19$ & $339.71 \pm 11.83$ & 33.4 & $371.91 \pm 9.42$ & $393.24 \pm 9.96$ & $0.1162(0.971)$ \\
\hline 19 & 16.5 & 4 & 75 & 20.73 & $301.25 \pm 4.55$ & $320.49 \pm 31.89$ & 25.1 & $353.94 \pm 18.90$ & $376.54 \pm 20.11$ & 0.1199 (0.986) \\
\hline 20 & 16.5 & 4 & 75 & 18.01 & $285.51 \pm 1.77$ & $303.25 \pm 1.88$ & 18.5 & $336.61 \pm 7.73$ & $357.52 \pm 8.21$ & $0.1270(0.992)$ \\
\hline RWS 1 & - & - & - & - & $215.60 \pm 5.77$ & $227.20 \pm 6.08$ & - & $347.78 \pm 26.97$ & $366.49 \pm 28.42$ & $0.0573(0.996)$ \\
\hline RWS 2 & - & - & - & - & $240.91 \pm 7.21$ & $252.50 \pm 7.56$ & - & $339.10 \pm 13.31$ & $355.41 \pm 13.95$ & 0.0737 (0.997) \\
\hline
\end{tabular}




\subsection{Empirical models following RSM}

\subsubsection{Statistical models}

In order to improve the understanding on the effects of the different AAS parameters on the digestion of wheat straw, three different empirical models were constructed based on the experiments run following the RSM. The first equation (eq.3) expresses the \% of COD solubilized as a function of the AAS parameters, while the two following equations (eq. 4 and eq.5) express the $\mathrm{CH}_{4}$ yield after 59 days (ultimate yield) and after 17 days (short term $\mathrm{CH}_{4}$ yield) respectively:

$$
\begin{gathered}
\text { \% sol COD }=4.20+0.91 A+0.94 D+0.02 A^{2} \text { (eq.3) } \\
\text { ultCH}_{4} \text { yield }=553.21+9.70 A+12.76 D-8.46 S L-0.53 A D-0.03 A S L-0.12 A^{2}+0.06 S L^{2} \text { (eq.4) } \\
\text { CH }_{4} \text { yield }_{17}=436.80+6.69 A+9.84 D-6.44 S L-0.25 A D-0.14 A^{2}+0.04 S L^{2} \text { (eq.5) }
\end{gathered}
$$

Where:

$\%$ sol $C O D$, the fraction of total COD solubilized after AAS

ultCH $\mathrm{H}_{4}$ yield, the cumulative $\mathrm{CH}_{4}$ yield of AAS-treated straw at the end of digestion expressed in $\mathrm{mL} / \mathrm{g}$ TS $\mathrm{CH}_{4}$ yield $17 d$, the cumulative $\mathrm{CH}_{4}$ yield of AAS-treated straw after 17 days of digestion, in $\mathrm{mL} / \mathrm{g} \mathrm{TS}$ $A$, the $\mathrm{NH}_{3}$ concentration of the reagent in $\% \mathrm{w} / \mathrm{w}$

$D$, the duration of AAS in days

$S L$, the solid-to-liquid ratio of the pretreatment mixture, expressed in g wheat straw/ L reagent

All models were found to be highly significant $(p \leq 0.0001)$ and no lack of fit was detected $(p=0.8548, p=0.5377$ and $p=0.5592$ for eq. 3, eq. 4 and eq. 5 respectively). The $\mathrm{R}^{2}$ (0.82 for eq.3 and 0.89 for eq. 4 and eq. 5) was in 
good agreement with the adjusted $\mathrm{R}^{2}$ (0.78 for eq. 3 and 0.83 for eq. 4 and eq. 5 ) indicating that the terms included in the equations are sufficient for describing the responses. Thus, the models can be trusted for navigating the design space.

Among the three AAS parameters tested, the $\mathrm{NH}_{3}$ concentration had the most significant influence on the ultimate $\mathrm{CH}_{4}$ yield as the main $(A)$ and quadratic $\left(A^{2}\right)$ effects were found to be highly significant $(p<0.001)$ as well as both interaction terms with $\mathrm{NH}_{3}(A \cdot D, A \cdot S L),(p=0.0002$ and $p=0.0215$ respectively). The interaction between the $\mathrm{NH}_{3}$ concentration and the duration of AAS was found to be the most influencing on the ultimate $\mathrm{CH}_{4}$ yield. The response surface graphs presented in Fig. 2 show how the prediction of the ultimate $\mathrm{CH}_{4}$ yield is affected by varying these two parameters at the three different levels of S:L ratio. Based on the surface graphs, it is clear that a reduction of the $\mathrm{NH}_{3}$ concentration used for the pretreatment has to be compensated by a longer duration for increasing the wheat straw digestibility. Interestingly, when both parameters are set at the lowest or at the highest levels, the efficiency of the pretreatment is reduced. Thus, harsh conditions (both high $\mathrm{NH}_{3}$ concentration and duration) are not in favor of an enhanced bioconversion of wheat straw, probably due to the formation of degradation compounds that are not converted to $\mathrm{CH}_{4}$. This is in agreement to other studies of AAS on lignocellulosic biomasses for improving bioconversion [37]. On the other hand, in a previous study [26] where $\mathrm{NH}_{3}$ was applied to wheat straw with heat application $\left(32.2-67.8^{\circ} \mathrm{C}\right)$, the interaction among $\mathrm{NH}_{3}$ concentration and duration was found not to be significant on the resulted biogas yield, and in fact the duration of AAS was reported to be the least important factor among temperature, $\mathrm{NH}_{3}$ concentration and duration of AAS. This can be explained due to the low range of duration tested in that study (up to 48 hours), as well as due to the strong interaction among temperature and $\mathrm{NH}_{3}$ concentration that could have covered the effect of the duration.

A comparison among the surface graphs at different S:L ratios (Fig.2) shows also the quadratic effect of this factor, which expresses that the ultimate $\mathrm{CH}_{4}$ yield is increased when the lowest or the highest $\mathrm{S}: \mathrm{L}$ ratio is applied, while the middle S:L ratio $(75 \mathrm{~g} / \mathrm{L})$ results to the poorest $\mathrm{CH}_{4}$ yield regardless the rest of conditions. This is also evident from Fig.3 where the ultimate $\mathrm{CH}_{4}$ yield is plotted as a function of the S:L ratio and the $\mathrm{NH}_{3}$ concentration. Not 
many studies of AAS have included the effect of the S:L ratio during the pretreatment on the $\mathrm{CH}_{4}$ yield. Nevertheless, it has been reported that a decrease of the S:L ratio is linked to an increased enzymatic digestibility or ethanol yield [38-40]. The main effect of the duration of AAS can be observed in Fig.3, where the response surface is elevated as duration increases from 1 to 4 and to 7 days. Due to the interaction of the duration and the $\mathrm{NH}_{3}$ concentration, this is more pronounced at low $\mathrm{NH}_{3}$ concentrations. When duration is minimum (1 day), then the conditions of AAS that result in an enhanced $\mathrm{CH}_{4}$ yield are narrowed to the maximum $\mathrm{NH}_{3}$ concentration (32\% $\mathrm{w} / \mathrm{w})$ and the minimum S:L ratio (50 g/L). These conditions are found to be the optimal for maximizing the final digestibility of wheat straw.

The importance of the duration of AAS for increased biomass digestibility has been observed in more studies [38, 41]. From an economic point of view, this factor is of critical importance. The duration of the process will determine the capacity of the pretreatment vessel in order to ensure a constant supply of pretreated biomass. In this sense, it could be desirable to increase the pretreatment duration and thus the capacity of the pretreatment vessel, in order to minimize the $\mathrm{NH}_{3}$ concentration and thus the energy input for the $\mathrm{NH}_{3}$ recovery process. In this study, no mixing took place during the pretreatment in order to minimize the energy input during the pretreatment process. However, mixing during AAS could improve the contact of the reagent with the biomass reducing this way the optimal duration.

The terms found to be significant on the short term $\mathrm{CH}_{4}$ yield were the same as for the ultimate $\mathrm{CH}_{4}$ yield, except for the interaction among the $\mathrm{NH}_{3}$ concentration and the $\mathrm{S}: \mathrm{L}$ ratio of AAS $(A \cdot S L)$, that appeared not to be that influencing on the short term efficiency of the pretreatment. On the contrary, the $\mathrm{NH}_{3}$ concentration $(A)$ still remained the most influencing factor as well as the duration of AAS $(D)$ and their interaction $(A \cdot D)$. The above results indicate that the S:L ratio applied can be chosen independently of the rest of parameters during the process configuration, facilitating thus the process design. The response surface graphs in Fig.4 show how the prediction of the short term $\mathrm{CH}_{4}$ yield is affected by the different levels of the two interacting parameters $(A$ and $D)$ at the three levels of S:L ratio. As it may be seen by comparing the three surface graphs (Fig. 4), the effect of the S:L 
ratio produces an elevation of the surface when it is set at $50 \mathrm{~g} / \mathrm{L}$ or $100 \mathrm{~g} / \mathrm{L}$, and the middle S:L ratio $(75 \mathrm{~g} / \mathrm{L})$ results to the lowest values for the $\mathrm{CH}_{4}$ yield at all combinations of $\mathrm{NH}_{3}$ concentration and duration of AAS. Based on the graphs it appears that the optimal conditions of AAS for increasing the short term $\mathrm{CH}_{4}$ yield of AAS-treated wheat straw correspond to $18 \% \mathrm{w} / \mathrm{w} \mathrm{NH}_{3}, 7$ days of duration and $50 \mathrm{~g} / \mathrm{L}$. The prediction of eq. 5 at these conditions corresponds to $337 \pm 11 \mathrm{~mL} / \mathrm{g}$ TS.

The fact that harsher conditions $\left(32 \% \mathrm{w} / \mathrm{w} \mathrm{NH}_{3}\right)$ were found to be optimal for maximizing the final degradability of the pretreated wheat straw in comparison to the optimal conditions for maximizing the short term $\mathrm{CH}_{4}$ yield (18\% w/w $\mathrm{NH}_{3}$ ), indicate that during the pretreatment some compounds could have been formed that were not easily converted by microbes to $\mathrm{CH}_{4}$ at the initial stages of the BMP tests. However, this bottleneck was temporary, as at the end, these compounds were utilized by the microbes resulting to the maximum ultimate $\mathrm{CH}_{4}$ yield observed.

Finally, modelling the fraction of solubilized COD after the pretreatment as a response of the AAS parameters (eq. 3) showed that mainly the $\mathrm{NH}_{3}$ concentration $(p<0.0001)$ was responsible for the extent of solubilization, followed by the duration of AAS $(p=0.0025)$. On the other hand, the S:L ratio was found to be statistically insignificant $(p>0.0500)$. Both influencing factors had a positive correlation with the fraction of COD solubilized. This is in agreement to previous studies where higher solubility of manure fibers [28] and rice straw [37] was observed at harsher conditions of AAS. Given that the conditions that maximize the soluble COD do not correspond to the same conditions that maximize the short term $\mathrm{CH}_{4}$ yield, it is clear that if only the solid fraction of pretreated wheat straw would be digested, the optimal conditions for maximizing the $\mathrm{CH}_{4}$ yield would probably be different. Thus, the empirical model for predicting the soluble COD as a function of the conditions was constructed in order to provide an indirect measurement of how much of the $\mathrm{CH}_{4}$ production potential would be lost if only the pretreated solids would be sent to $\mathrm{AD}$. While the exact production may vary depending on the technology used for the separation of the solid and liquid fractions, the soluble COD can be used for orienting a process configuration. 

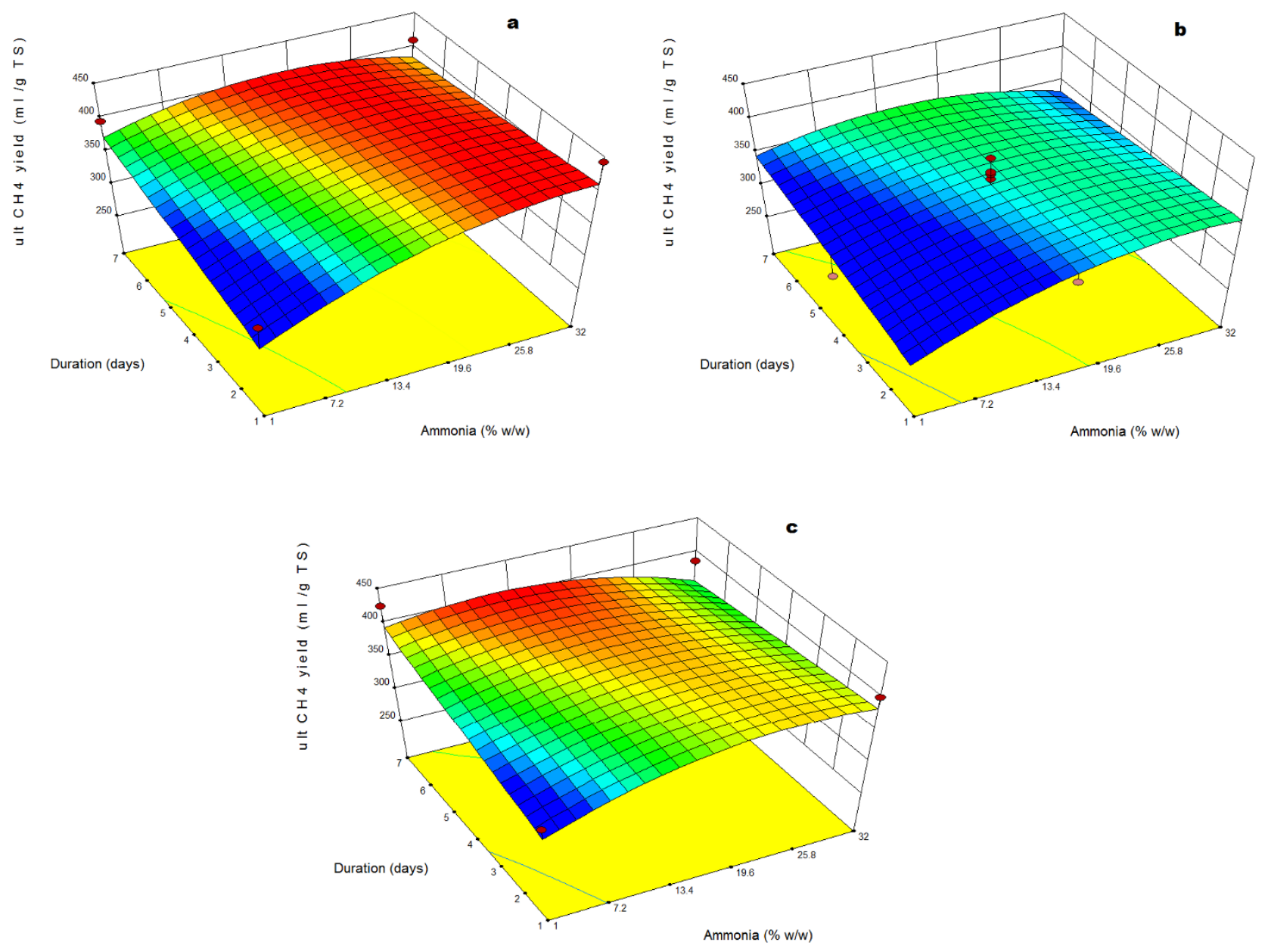

Fig. 2 Response surface graphs based on equation 4. The predicted ultimate $\mathrm{CH}_{4}$ yield of AAS-treated wheat straw is plotted as a function of the $\mathrm{NH}_{3}$ concentration and the duration of AAS. The S: $\mathrm{L}$ ratio is set constant in each graph, corresponding to 50,75 and $100 \mathrm{~g} / \mathrm{L}$ in a, b and c respectively. Dots in figures correspond to the experimental points. 

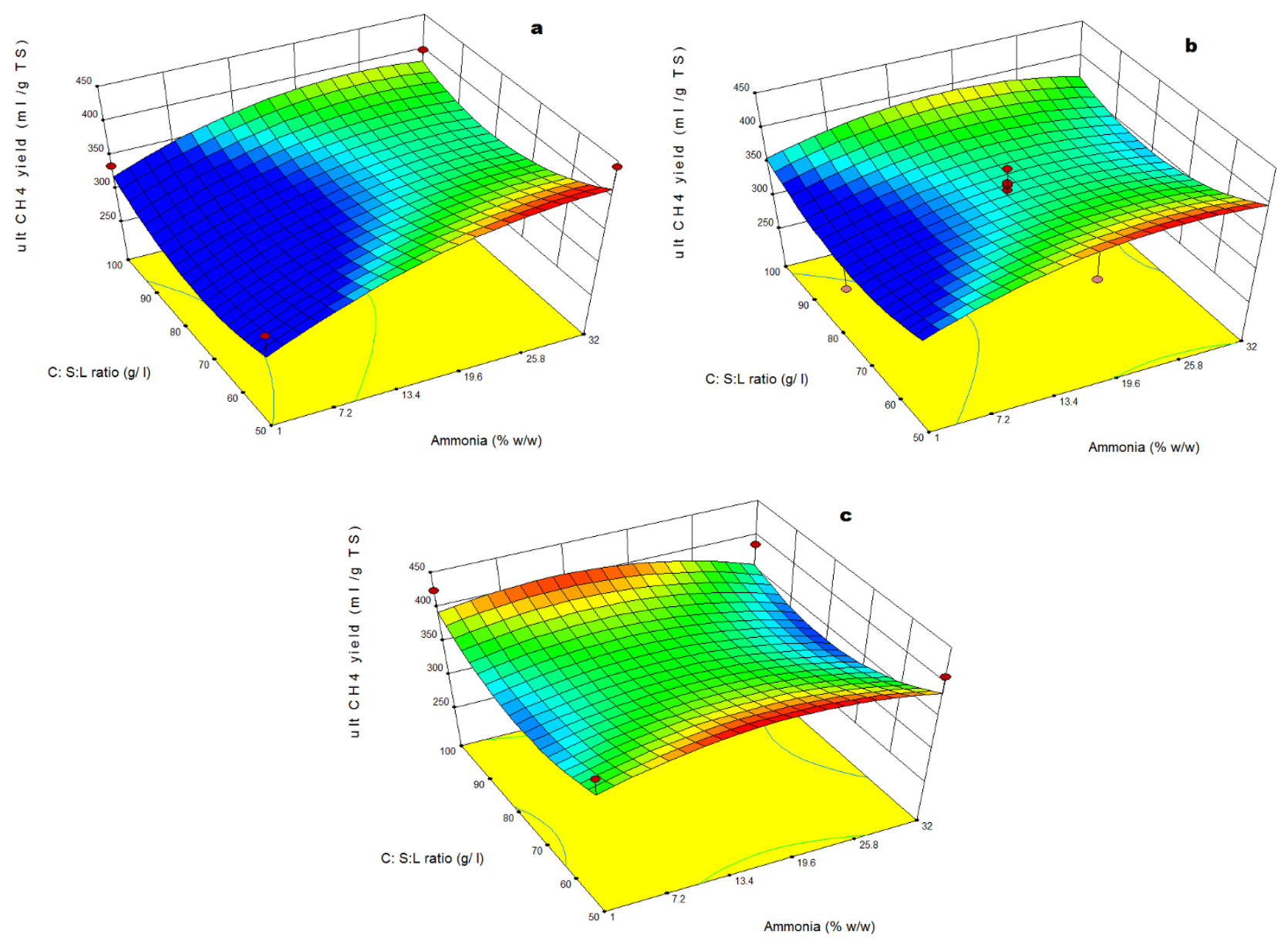

Fig. 3 Response surface graphs based on equation 4. The predicted ultimate $\mathrm{CH}_{4}$ yield of AAS-treated wheat straw is plotted as a function of the $\mathrm{NH}_{3}$ concentration and the $\mathrm{S}: \mathrm{L}$ ratio. The duration of AAS is set constant in each graph, corresponding to 1,4 and 7 days in a, b and c respectively. Dots in figures correspond to the experimental points. 



Fig. 4 Response surface graphs of equation 5. The surface represents the predicted $\mathrm{CH}_{4}$ yield of AAS-treated wheat straw after 17 days of digestion as a function of the duration and $\mathrm{NH}_{3}$ concentration under which the pretreatment takes place. The S:L ratio is set constant to 50 g/L, $75 \mathrm{~g} / \mathrm{L}$ and $100 \mathrm{~g} / \mathrm{L}$ in a, b and c respectively. Dots in figures correspond to the experimental points.

\subsubsection{Validation of empirical models and theoretical calculations}

In order to validate the empirical models produced from the experimental data of this study (eq. 3, eq. 4, and eq. 5), the optimal conditions for maximizing the short term $\mathrm{CH}_{4}$ yield were applied to wheat straw in three independent runs, and BMP experiments were set in triplicates for each run. The conditions applied were 18\% w/w of $\mathrm{NH}_{3}$ (aq.), 7 days of duration and $50 \mathrm{~g}$ wheat straw/L reagent. The experimental results obtained by the 
wheat straw treated under these conditions resulted on average in $326 \pm 17 \mathrm{~mL} / \mathrm{g}$ TS short term $\mathrm{CH}_{4}$ yield, $393 \pm$ $17 \mathrm{~mL} / \mathrm{g}$ TS ultimate $\mathrm{CH}_{4}$ yield and $20.36 \pm 1.43 \%$ COD solubilized. As shown in Table 3, the experimental results were all within the prediction range of each model. The hydrolysis rate of the wheat straw treated under optimal conditions was $0.1080\left(\mathrm{R}^{2}=0.9907\right)$, reaching nearly a 65\% increase in comparison to the RWS. The theoretical $\mathrm{CH}_{4}$ yield of the wheat straw used in this study was found to be $446 \mathrm{~mL} / \mathrm{g} \mathrm{TS}$, corresponding to $468 \mathrm{~mL} / \mathrm{g} \mathrm{VS}$ if taking into consideration the TS/VS ratio of the biomass. This value is similar to values reported in other studies, e.g. $444 \mathrm{~mL} / \mathrm{g}$ VS [42], $426 \mathrm{~mL} / \mathrm{g}$ VS [43], $432 \mathrm{~mL} / \mathrm{g}$ VS [13] and $436 \mathrm{~mL} / \mathrm{g}$ VS [44]. The digestion tests of RWS produced an average of $228 \mathrm{~mL} / \mathrm{g}$ TS corresponding to $51.2 \%$ of the theoretical $\mathrm{CH}_{4}$ yield, while the wheat straw treated under optimal AAS conditions resulted in 73.1\% (326 mL/g TS). In an earlier study where AAS was applied on wheat straw with 32\% w/w for 3 days, a 41\% increase of the short term $\mathrm{CH}_{4}$ yield was reported [22]. AAS at low temperature under optimal conditions produced a $43 \%$ increase of the short term $\mathrm{CH}_{4}$ yield as compared to the RWS. This confirms the strong interaction among $\mathrm{NH}_{3}$ concentration and duration, as the increase of duration (from 3 to 7 days) permits reducing the concentration of $\mathrm{NH}_{3}$ significantly (from 32 to $18 \%$ w/w) resulting to a slightly higher increase of the $\mathrm{CH}_{4}$ yield. Additionally, it is noteworthy that the optimized application of AAS involving heat application $\left(51^{\circ} \mathrm{C}\right)$ resulted to a similar increase of biogas yield as found in this study with AAS at ambient temperature [26]. Therefore, in order to avoid the energy input of heat requirements during AAS, it was shown that the duration can be increased without losing the $\mathrm{CH}_{4}$ production potential.

Table 3 Prediction of responses under optimal conditions of AAS and Validation of empirical models

\begin{tabular}{lcccccccc}
\hline Response & Model & Mean & Median & Observed & Std Dev* & SE Mean & 95\% CI low & 95\% CI high \\
\hline CH4 yield $17^{2}$ & eq.5 & 337.04 & 337.04 & $325.87 \pm 16.74$ & 11.12 & 7.86 & 319.91 & 354.18 \\
ultCH4 yield & eq.4 & 408.61 & 408.61 & $393.26 \pm 17.42$ & 13.06 & 9.24 & 388.26 & 428.96 \\
\% sol COD & eq.3 & 21.42 & 21.42 & $20.36 \pm 1.43$ & 2.46 & 1.10 & 19.07 & 23.77 \\
\hline
\end{tabular}

*Std Dev stands for standard deviation as predicted by the model and CI for Confidence Interval. Observed values correspond to average values of triplicates \pm standard deviation 
In comparison to other pretreatments tested so far on wheat straw, AAS appears to have a relatively high influence on the $\mathrm{CH}_{4}$ yield of this biomass. Nevertheless the highest increase of $\mathrm{CH}_{4}$ yield reported so far from wheat straw has been by $\mathrm{NaOH}$ pretreatment [45], and corresponds to $111.6 \%$. A recent review on pretreatments that have been tested on wheat straw and the resulted increase can be found by Croce et al. [4]. Alkaline reagents, and especially $\mathrm{NaOH}$, appear to be the most efficient on increasing the digestibility of lignocellulosic biomasses [46]. However, $\mathrm{NaOH}$ is not easy to recover, so a $\mathrm{NaOH}$ pretreatment would be associated to the additional cost of chemicals, also for neutralizing the pretreatment mixture prior to digestion. Additionally, the resulting high sodium concentration might present a problem for applying the digestate to land [46]. Thus, AAS coupled to an $\mathrm{NH}_{3}$ recovery process could be more favorable for an actual application when taking into consideration these environmental aspects. As commented in section 1, the high potential of AAS resides on the nature of this alkaline reagent that could permit an easier recycling. While some economic aspects of ammonia pretreatments have been discussed earlier [47], a techno-economic analysis based on the different possible AAS configurations at ambient temperature and including an $\mathrm{NH}_{3}$ recovery process is still pending.

\subsection{Effect of optimized AAS on composition of wheat straw}

The effect of AAS on wheat straw, pretreated under optimal conditions, was further investigated by comparing its composition to the raw biomass (Table 4). A significant solubilization of the hemicellulose fraction was observed, indicated by a $60.8 \%$ and $67.5 \%$ reduction of the xylan and arabinan content of the solid matrix of wheat straw respectively. Part of the solubilized sugars were detected in the liquid fraction of the pretreated biomass together with a significant increase of the acetic acid content (1.52\% TS from $0.33 \%$ TS from the raw biomass). The lignin fraction was also solubilized, resulting to a lignin removal of $9 \%$ from the solid matrix. Solubilization of hemicellulose and lignin might result to formation of inhibitory by-products, such as HMF, furfurals and lignin derivatives [15]. Nevertheless, these byproducts are usually formed by harsh pretreatment conditions where heat 
application or acids are involved. Under mild conditions of AAS, it has been reported that no such by-products are formed $[27,48]$. Therefore, the fraction of hemicellulose not recovered in the form of oligosaccharides or free sugars in the liquid fraction probably resulted in other degradation compounds [49].

An increased fraction of $\mathrm{N}$ was detected in the pretreated biomass, probably due to $\mathrm{N}$ chemical fixation that occurred during AAS. As commented in section 1, one of the benefits when using agricultural straws for AD is the high $\mathrm{C} / \mathrm{N}$ ratio that permits improving the co-digestion with $\mathrm{N}$-rich wastes. The decrease of the $\mathrm{C} / \mathrm{N}$ ratio due to $\mathrm{N}$ chemical fixation during the pretreatment results thus to a reduced flexibility on co-digesting. Nevertheless, the $\mathrm{C} / \mathrm{N}$ ratio of the pretreated biomass itself stands within the optimal conditions for $\mathrm{AD}$ [7]. Even though the extent of $\mathrm{N}$ chemical fixation observed might not present an inhibition problem for the AD process, the fate of the reagent-derived $\mathrm{N}$ during the pretreatment and $\mathrm{AD}$ should be further investigated. Early studies have investigated the reaction of $\mathrm{NH}_{3}$ with lignocellulosic cell wall compounds like polysaccharides, reducing sugars and lignin and a series of nitrogenous compounds have been reported to occur through ammonolysis or Maillard-type reactions [50-52]. However, these reactions usually occur at high temperature and more research is needed to understand how $\mathrm{NH}_{3}$ reacts with lignocellulose at ambient temperature.

Overall the total solid recovery after the pretreatment was very high for the AAS under optimal conditions (97.96\%), similarly as for the rest of experiments with AAS under varying conditions. The mass balance of the optimally AAS-treated wheat straw (Fig.5) indicates that a large fraction of the total COD is recovered in the form of $\mathrm{CH}_{4}$, while only $9.7 \%$ of the total COD has been calculated to remain in the digestate. On the contrary, in the case of RWS, only $76.9 \%$ of COD was recovered in the form of $\mathrm{CH}_{4}$ (Fig.5), and $23.1 \%$ corresponded to the fraction of the digestate. It should be mentioned here that the above estimation is indicative given that the COD determination of wheat straw was accompanied by a variation of ca. 11\% (see section 2.1).

The AAS pretreatment appears thus to be very promising for improving the conversion of wheat straw to $\mathrm{CH}_{4}$. A drawback of the process followed could be the addition of tap water prior to the evaporation step (see section 2.2). 
Nevertheless, the liquid fraction of the AD effluent could be used instead, as the separation of AD effluent to a solid and liquid fraction is common in many biogas plants. This could eliminate the need of clean tap water and consequently reduce the cost of the process. In this line, preliminary experiments showed that adding centrifuged effluent from a manure-based AD process instead of tap water had no adverse effect on the efficiency of the process.

Table 4 Composition of RWS and optimally AAS-treated wheat straw

\begin{tabular}{|c|c|c|}
\hline Component & RWS (\% TS) & $\begin{array}{l}\text { AAS-treated wheat } \\
\text { straw (\% TS } \text { initial })\end{array}$ \\
\hline Dry matter* & $93.99 \pm 0.14$ & $3.70 \pm 0.10$ \\
\hline Total Organic N & $0.66 \pm 0.03$ & $1.02 \pm 0.05$ \\
\hline $\mathrm{C} / \mathrm{N} * *$ & $63.21 \pm 0.65$ & $27.98 \pm 3.89$ \\
\hline Total Solid Recovery \%*** & - & 97.96 \\
\hline Glucan & $41.07 \pm 2.94$ & $43.41 \pm 1.27$ \\
\hline Xylan & $23.77 \pm 1.18$ & $9.32 \pm 0.43$ \\
\hline Arabinan & $3.26 \pm 0.10$ & $1.06 \pm 0.04$ \\
\hline Acid-insoluble lignin & $16.24 \pm 0.73$ & $14.78 \pm 0.93$ \\
\hline Total Ash & $5.32 \pm 0.91$ & $5.21 \pm 0.01$ \\
\hline Extractives \& volatiles & $14.58 \pm 0.04$ & $20.31 \pm 0.38$ \\
\hline Water extractives & $9.44 \pm 0.23$ & $17.58 \pm 1.33$ \\
\hline Ethanol extractives & $2.13 \pm 0.72$ & $3.20 \pm 0.37$ \\
\hline \multicolumn{3}{|l|}{ Soluble fraction } \\
\hline Soluble Glucose & $0.31 \pm 0.03$ & $0.78 \pm 0.00$ \\
\hline Soluble Xylose & $0.55 \pm 0.06$ & $4.42 \pm 0.02$ \\
\hline Soluble Arabinose & $0.16 \pm 0.02$ & $1.12 \pm 0.00$ \\
\hline Acid-soluble lignin & $0.40 \pm 0.00$ & $2.17 \pm 0.01$ \\
\hline Free sugars & $0.33 \pm 0.01$ & $0.10 \pm 0.02$ \\
\hline Acetic Acid & $0.33 \pm 0.00$ & $1.52 \pm 0.01$ \\
\hline $\mathrm{NH}_{4}{ }^{+}-\mathrm{N}$ content & $0.01 \pm 0.00$ & $0.05 \pm 0.00$ \\
\hline
\end{tabular}



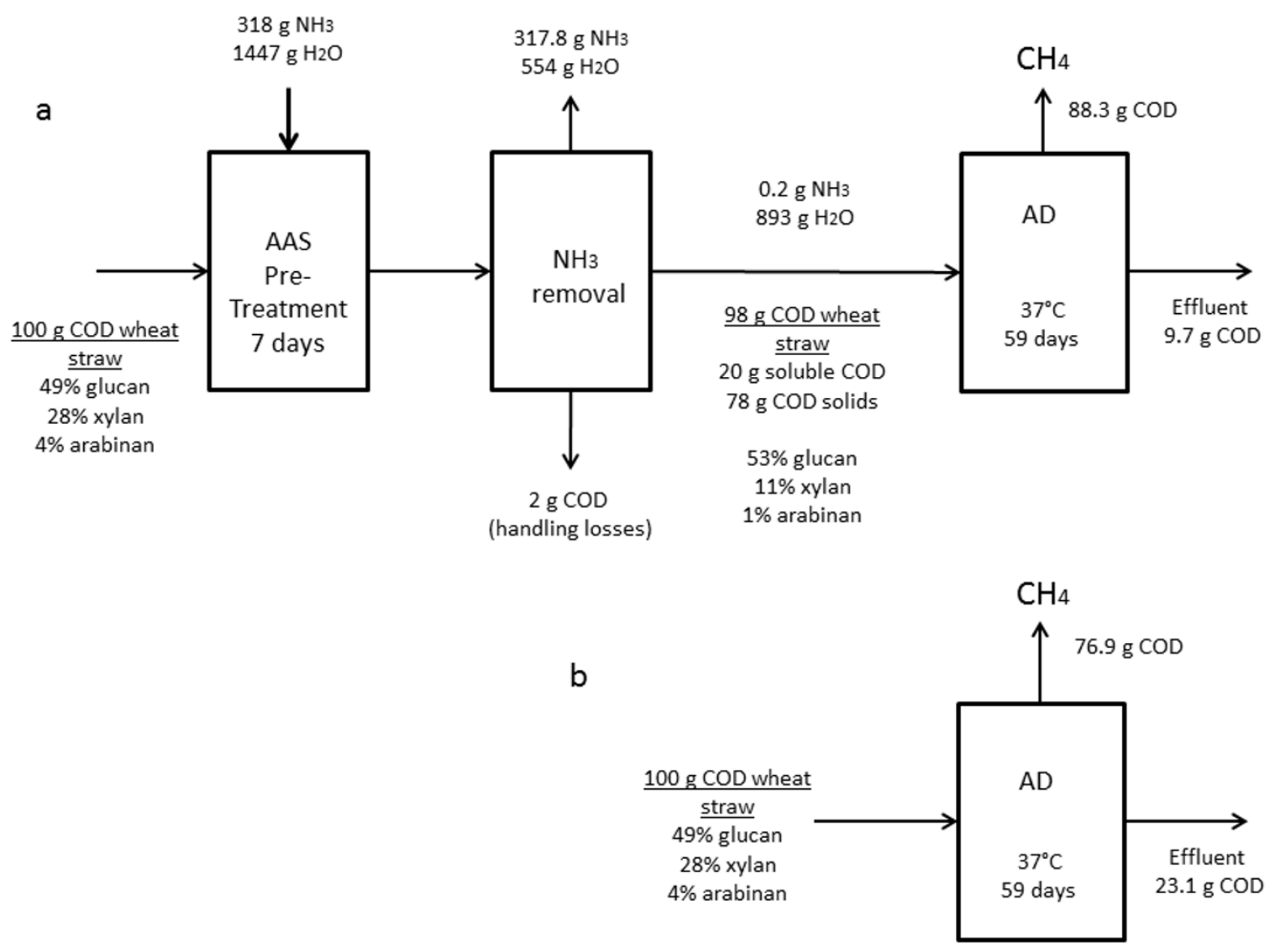

Fig. 5 Overall Mass balance of (a) optimally pretreated wheat straw based on the validation experiments run, (b) raw wheat straw.

\section{Conclusions}

A strong interaction among $\mathrm{NH}_{3}$ concentration and treatment duration was observed after applying AAS on wheat straw as a pretreatment method for enhancement of $\mathrm{CH}_{4}$ production. This provides certain flexibility on a successful application of AAS on wheat straw. The optimal conditions for the short term $\mathrm{CH}_{4}$ yield corresponded to $18 \%$ w/w $\mathrm{NH}_{3}$ (aq.), 7 days of digestion and $50 \mathrm{~g}$ straw/L reagent, and led to a $43 \%$ increase as compared to the raw biomass. It has been shown that a high increase of the $\mathrm{CH}_{4}$ yield of wheat straw can be obtained when pretreated with AAS under ambient temperature, and empirical models were constructed for facilitating the further 
evaluation of different configurations. The significant solubilization of the solid matrix of wheat straw after the pretreatment indicated the importance of using the whole fraction of the biomass (solid and liquid) for enhancing the $\mathrm{CH}_{4}$ production. Compositional analysis of the optimally pretreated wheat straw showed that the fraction solubilized was mainly derived from hemicellulose, while a moderate lignin removal occurred. Furthermore, it was shown that part of the reagent $\mathrm{N}$ is bound to the pretreated biomass increasing the final $\mathrm{C} / \mathrm{N}$ of wheat straw. This study points to the necessity of identifying the nitrogenous compounds formed during AAS under ambient temperature, in order to study the fate of the reagent derived $\mathrm{N}$ during $\mathrm{AD}$.

\section{Acknowledgements}

The authors would like to thank Energinet.dk for the funding of the work presented here under the project AMMONOX - Ammonia for enhancing biogas yield \& reducing $\mathrm{NO}_{\mathrm{x}}\left(\mathrm{N}^{0} 12069\right)$ and the CHEC Research Center for facilitating access to Elemental Analysis equipment.

\section{References}

1. The European Parliament and the Council of the European Union: Directive 2009/28/EC of the European Parliament and of the Council of 23 April 2009. Off J Eur Union 140, 16-62 (2009)

2. Scarlat, N., Dallemand, J., Monforti-Ferrario, F., Nita, V.: The role of biomass and bioenergy in a future bioeconomy : Policies and facts. Environ Dev. 15, 3-34 (2015)

3. Scarlat, N., Martinov, M., Dallemand, J.-F.: Assessment of the availability of agricultural crop residues in the European Union : Potential and limitations for bioenergy use. Waste Manag. 30, 1889-1897 (2010)

4. Croce, S., Wei, Q., D’Imporzano, G., Dong, R., Adani, F.: Anaerobic digestion of straw and corn stover: The effect of biological process optimization and pre-treatment on total bio-methane yield and energy performance. Biotechnol Adv. 34, 1289-1304 (2016) 
5. Zhang, R. and Jenkins, B. M.: Commercial uses of straw., Agricultural Mechanization and Automation, II, . In: Encyclopedia of Life Support Systems (EOLSS), pp308-341 ,UNESCO, Paris, University College Dublin, Ireland, 2009

6. Hills, D. J,. Roberts, D. W.: Anaerobic digestion of dairy manure and field crop residues. Agric Wastes 3, 179-189 (1981)

7. Wang, X., Yang, G., Feng, Y., Ren, G., Han, X.: Optimizing feeding composition and carbon-nitrogen ratios for improved methane yield during anaerobic co-digestion of dairy, chicken manure and wheat straw. Bioresour Technol. 120, 78-83 (2012)

8. Krishania, M., Vijay, V. K., Chandra, R.: Methane fermentation and kinetics of wheat straw pretreated substrates co-digested with cattle manure in batch assay. Energy 57, 359-367 (2013)

9. Awais, M., Alvarado-Morales, M., Tsapekos, P., Gulfraz, M., Angelidaki, I.: Methane production and kinetic modeling for co- digestion of manure with lignocellulosic residues. Energy \& Fuels 30, 1051610523 (2016)

10. Pavlostathis, S. G., Gossett, J. M.: Alkaline Treatment of Wheat Straw for Increasing Anaerobic Biodegradability. Biotechnol Bioeng. XXVII, 334-344 (1985)

11. Hashimoto, A. G.: Pretreatment of Wheat Straw for Fermentation to Methane. Biotechnol Bioeng, XXVIII, 1857-1866 (1986)

12. Alvarado-Morales, M., Tsapekos, P., Awais, M., Gulfraz, M., Angelidaki, I.: TiO 2 / UV based photocatalytic pretreatment of wheat straw for biogas production. Anaerobe (2016)

13. Møller, H. B., Sommer, S. G., Ahring, B. K.: Methane productivity of manure, straw and solid fractions of manure. Biomass Bioenergy, 26, 485-495 (2004) 
14. Mosier, N.: Features of promising technologies for pretreatment of lignocellulosic biomass. Bioresour Technol. 96, 673-686(2005)

15. Hendriks, A. T. W. M., Zeeman, G.: Pretreatments to enhance the digestibility of lignocellulosic biomass. Bioresour Technol. 100, 10-18 (2009)

16. Taherzadeh, M. J., Karimi, K.: Pretreatment of Lignocellulosic Wastes to Improve Ethanol and Biogas Production: A Review. Int J Mol Sci. 9, 1621-1651 (2008)

17. Lymperatou, A., Gavala, H. N., Esbensen, K. H., Skiadas, I. V: AMMONOX: Ammonia for Enhancing Biogas Yield and Reducing NOx-Analysis of Effects of Aqueous Ammonia Soaking on Manure Fibers. Waste Biomass Valori. 6, 449-457 (2015)

18. Kim, J. S., Lee, Y. Y., Kim, T. H.: A review on alkaline pretreatment technology for bioconversion of lignocellulosic biomass. Bioresour Technol. 199, 42-48 (2016)

19. Himmelsbach, J. N., Isci, A., Raman, D. R., Anex, R. P.: Design Testing pilot aqueous ammonia soaking biomass pretreatment system. Appl Eng Agric. 25, 953-959 (2009)

20. Song, Z., Yang, G., Guo, Y., Zhang, T.: Comparison of two chemical pretreatments of rice straw for biogas production by anaerobic digestion. bioresources 7, 3223-3236 (2012)

21. Jurado, E., Skiadas, I. V, Gavala, H. N.: Enhanced methane productivity from manure fibers by aqueous ammonia soaking pretreatment. Appl Energy 109, 104-111 (2013)

22. Jurado, E., Gavala, H. N., Skiadas, I. V: Enhancement of methane yield from wheat straw, miscanthus and willow using aqueous ammonia soaking. Environ Technol. 34, 2069-2075 (2013)

23. Mirtsou-Xanthopoulou, C., Jurado, E., Skiadas, I. V, Gavala, H. N.: Effect of Aqueous Ammonia Soaking on the Methane Yield and Composition of Digested Manure Fibers Applying Different 
Ammonia Concentrations and Treatment Durations. Energies 7, 4157-4168 (2014)

24. Yang, D., Pang, Y., Yuan, H., Chen, S., Ma, J., Yu, L., Li, X.: Enhancing Biogas Production from Anaerobically Digested Wheat Straw Through Ammonia Pretreatment. Chinese J Chem Eng. 22, 576582 (2014).

25. Song, Z., GaiheYang, Liu, X., Yan, Z., Yuan, Y., Liao, Y.: Comparison of Seven Chemical Pretreatments of Corn Straw for Improving Methane Yield by Anaerobic Digestion. PLoS One 9, e93801 (2014)

26. Li, Y., Merrettig-Bruns, U., Strauch, S., Kabasci, S., Chen, H.: Optimization of ammonia pretreatment of wheat straw for biogas production. J Chem Technol Biotechnol. 90, 130-138 (2015)

27. Antonopoulou, G., Gavala, H. N., Skiadas, I. V., Lyberatos, G.: The Effect of Aqueous Ammonia Soaking Pretreatment on Methane Generation Using Different Lignocellulosic Biomasses. Waste Biomass Valori. 6, 281-291 (2015)

28. Lymperatou, A., Gavala, H. N., Skiadas, I. V: Optimization of Aqueous Ammonia Soaking of manure fibers by Response Surface Methodology for unlocking the methane potential of swine manure. Bioresour Technol. 244, 509-516 (2017)

29. Angelidaki, I., Alves, M., Bolzonella, D., Borzacconi, L., Campos, J.L., Guwy, A.J., Kalyuzhnyi, S., Jenicek, P., van Lier, J.B.: Defining the biomethane potential ( BMP ) of solid organic wastes and energy crops : a proposed protocol for batch assays. Water Sci Technol. 59, 927-934 (2009)

30. Sluiter, A., Ruiz, R., Scarlata, C., Sluiter, J., Templeton, D.: Determination of Extractives in Biomass NREL/TP-510-42619., Colorado, USA, (2008)

31. Sluiter, A., Hames, B., Ruiz, R., Scarlata, C., Sluiter J., Templeton, D., Crocker, D.: Determination of Structural Carbohydrates and Lignin in Biomass NREL/TP-510-42618., Colorado, USA, (2011) 
32. Hyman, D., Sluiter, A., Crocker, D., Johnson, D., Sluiter, J., Black, S., Scarlata, C.: Determination of Acid Soluble Lignin Concentration Curve by UV-Vis Spectroscopy NREL/TP-510-42617, (2008)

33. Bjerre, A. B., Plöger, A., Simonsen, T., Woidemann, A., \& Schmidt, A. S.: Quantification of solubilized hemicellulose from pretreated lignocellulose by acid hydrolysis and high-performance liquid chromatography., Forskningscenter Risoe. Risoe-R; No. 855(EN), Roskilde, Denmark, (1996)

34. APHA: Standard Methods for the Examination of Water and Wastewater, 21st ed.: American Public Health Association/American Water Works Association/Water Pollution Control Federation, Washington DC (2005)

35. Barakat, A., Monlau, F., Steyer, J. P., Carrère, H.: Effect of lignin-derived and furan compounds found in lignocellulosic hydrolysates on biomethane production. Bioresour Technol. 104, 90-99 (2012)

36. Siddique, M. N. I., Wahid, Z. A.: Achievements and perspectives of anaerobic co-digestion: A review. J Clean Prod, 194, 359-371 (2018).

37. Ko, J. K., Bak, J.S., Jung, M.W., Lee, H.J., Choi, I.G., Kim, T.H., Kim, K.H.: Ethanol production from rice straw using optimized aqueous-ammonia soaking pretreatment and simultaneous saccharification and fermentation processes. Bioresour Technol. 100, 4374-4380 (2009)

38. Kim, T. H, Lee, Y. Y.: Pretreatment of Corn Stover by Soaking in Aqueous Ammonia at Moderate Temperatures. Appl Biochem Biotechnol. 136-140, 81-92 (2007)

39. Li, X., Kim, T. H.: Low-liquid pretreatment of corn stover with aqueous ammonia. Bioresour Technol. 102, 4779-4786 (2011)

40. Yoo, C. G., Nghiem, N. P., Hicks, K. B., Kim, T. H.: Maximum Production of Fermentable Sugars from Barley Straw Using Optimized Soaking in Aqueous Ammonia ( SAA ) Pretreatment. Appl Biochem 
Biotechnol. 169, 2430-2441 (2013)

41. Li, X., Kim, T. H., Nghiem, N. P.: Bioethanol production from corn stover using aqueous ammonia pretreatment and two-phase simultaneous saccharification and fermentation (TPSSF). Bioresour Technol. 101, 5910-5916 (2010)

42. Ferreira, L. C., Donoso-Bravo, A., Nilsen, P. J., Fdz-Polanco, F., Pérez-Elvira, S. I.: Influence of thermal pretreatment on the biochemical methane potential of wheat straw. Bioresour Technol. 143, 251-257 (2013)

43. Kaparaju, P., Serrano, M., Thomsen, A. B., Kongjan, P., and Angelidaki, I.: Bioethanol, biohydrogen and biogas production from wheat straw in a biorefinery concept. Bioresour Technol. 100, 2562-2568 (2009)

44. Bauer, A., Leonhartsberger, C., Bosch, P., Amon, B., Friedl, A., Amon, T.: Analysis of methane yields from energy crops and agricultural by-products and estimation of energy potential from sustainable crop rotation systems in EU-27. Clean Technol Environ Policy. 12, 153-161 (2010)

45. Chandra, R., Takeuchi, H., Hasegawa, T., Kumar, R.: Improving biodegradability and biogas production of wheat straw substrates using sodium hydroxide and hydrothermal pretreatments. Energy 43, 273-282 (2012)

46. Carrère, H., Antonopoulou, G., Affes, R., Passos, F., Battimelli, A., Lyberatos, G., Ferrer, Y.: Review of feedstock pretreatment strategies for improved anaerobic digestion: From lab-scale research to full-scale application. Bioresour Technol. 199, 386-397 (2016)

47. Tao, L., Aden, A., Elander, R.T., Pallapolu, V.R., Lee, Y.Y., Garlock, R.J., Balan, V., Dale, B.E., Kim, Y., Mosier, N.S., Ladisch, M. R., Falls, M., Holtzapple, M. T., Sierra, R., Shi, J., Ebrik, M. A., Redmond, T., Yang, B., Wyman, C. E., Hames, B., Thomas, S., Warner, R. E.: Process and 
technoeconomic analysis of leading pretreatment technologies for lignocellulosic ethanol production using switchgrass. Bioresour Technol. 102, 11105-11114 (2011)

48. Kim, T. H., Lee, Y. Y.: Pretreatment of Corn Stover by Soaking in Aqueous Ammonia. Appl Biochem Biotechnol. 121-124, 1119-1132 (2005)

49. Du, B.,Sharma, L.N., Becker, C., Chen, S.F., Mowery, R.A., van Walsum, G.P., Chambliss, C.K.: Effect of varying feedstock-pretreatment chemistry combinations on the formation and accumulation of potentially inhibitory degradation products in biomass hydrolysates. Biotechnol Bioeng. 107, 430-440 (2010).

50. Chundawat, S. P. S., Vismeh, R., Sharma, L.N., Humpula, J.F., da Costa Sousa, L., Chambliss, C.K., Jones, A.D., Balan, V., Dale, B.E.: Multifaceted characterization of cell wall decomposition products formed during ammonia fiber expansion ( AFEX ) and dilute acid based pretreatments. Bioresour Technol. 101, 8429-8438 (2010)

51. Kort, M. J.: Reactions of Free Sugars with Aqueous Ammonia. In: R. S. Tipson and D. Horton, (Eds.) Advances in Carbohydrate Chemistry and Biochemistry 25, pp 311-349. New York: Academic Press, Inc. (1970)

52. Balan, V., da Costa Sousa, L., Chundawat, S. P. S., Humpula, J., Dale, B. E.: Overview to Ammonia Pretreatments for Lignocellulosic Biorefineries. Dyn Biochem Process Biotechnol Mol Biol. 6, 1-11 (2012) 